\title{
Lexis
}

Journal in English Lexicology

Book reviews | 2007

\section{Dirk GEERAERTS, Words and Other Wonders - Papers on Lexical and Semantic Topics}

Mouton de Gruyter, 2006, 503 pages

\section{Craig Hamilton}

\section{OpenEdition}

Journals

\section{Electronic version}

URL: http://journals.openedition.org/lexis/1840

DOI: $10.4000 /$ lexis. 1840

ISSN: 1951-6215

\section{Publisher}

Université Jean Moulin - Lyon 3

\section{Electronic reference}

Craig Hamilton, « Dirk geeraerts, Words and Other Wonders - Papers on Lexical and Semantic Topics », Lexis [Online], Book reviews, Online since 30 March 2007, connection on 23 September 2020. URL : http://journals.openedition.org/lexis/1840 ; DOI : https://doi.org/10.4000/lexis.1840

This text was automatically generated on 23 September 2020.

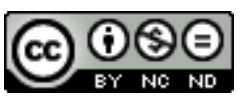

Lexis is licensed under a Creative Commons Attribution-NonCommercial-NoDerivatives 4.0 International License. 


\title{
Dirk GEERAERTS, Words and Other Wonders - Papers on Lexical and Semantic Topics
}

Mouton de Gruyter, 2006, 503 pages

\author{
Craig Hamilton
}

\section{REFERENCES}

\section{Dirk Geeraerts}

Words and Other Wonders - Papers on Lexical and Semantic Topics. Mouton de Gruyter, «Cognitive Linguistics Research 33 », 2006. ISBN : 978-3110190427, Prix : $83.51 €$, 503 pages

1 Dirk Geeraerts is without any doubt a leading cognitive linguist. In this book, he conveniently gathers together in one place seventeen articles he published between 1988 and 2003. The articles, which are grouped into six sections, mainly address methodological problems facing lexical semanticists, who comprise this book's primary audience. However, as my description of the book below aims to reveal, many other scholars in linguistics can find plenty of food for thought in this stimulating collection. As this book suggests, words are indeed wonders.

2 In chapter 1, 'Prospects and Problems of Prototype Theory,' Geeraerts explains that prototype theory appeared as an answer to the problem of the 'checklist theory' of categories, whereby items were considered members of categories according to whether or not they fulfilled necessary and sufficient criteria for membership. Geeraerts also implies that importing prototype theory into linguistics solves a problem created by Chomsky, who awkwardly argued that linguistics was a cognitive science while overlooking data from other cognitive sciences that would have truly supported his plea. As Geeraerts argues, there are four characteristics of prototypicality's extensional and intensional dimensions. First, categories are not 
checklists. Second, categories demonstrate family resemblance. Third, categories exhibit degrees of membership: some prototypes (e.g. robin) are simply better examples of the BIRD category than others (e.g. penguin). Fourth, categories have fuzzy boundaries. For the idealist, the mind is neat although the world is fuzzy. For the objectivist, science is neat although everyday language is fuzzy. The challenge for the cognitive linguist, according to Geeraerts, is to steer clear of these philosophical dichotomies even if the very concept of the prototype (as developed by Rosch's followers) may be more vague than we would sometimes like.

In chapter 2, 'Where Does Prototypicality Come From?' Geeraerts explains that gradience and salience are central to lexical semantic structure. Evidence for his claim comes from his analysis of two Dutch words, 'vernielen' (to destroy) and 'vernieligen' (to annihilate). Both words had the same usage range in the $19^{\text {th }}$ century although that is really no longer the case now. The slight difference in the range of application for these near-synonyms seems to arise from their different prototypical structures. Whereas there may be material that survives destruction when 'vernielen' is used, there may be nothing left when 'vernieligen' is used. Thus, 'vernielen' may be used in situations with material objects while 'vernieligen' may be used in situations with abstract entities. For example, hope may be 'annihilated' while electrical wire may be 'destroyed.' For Geeraerts, prototypicality exists because it is 'cognitively advantageous' (p. 42). Categories are stable over time yet flexible enough to adapt to new situations. As Geeraerts appropriately concludes in this chapter, prototypicality may have functional as well as conceptual origins.

4 In chapter 3, 'The Semantic Structure of Dutch over,' Geeraerts tackles the preposition of choice in cognitive linguistics. Whereas Cuyckens saw thirteen different senses of 'over' in Dutch, Geeraerts finds at least sixteen. Geeraerts' three main insights entail (1) the influence motion, fictive motion, and zero motion have on the semantics of 'over'; (2) whether or not the landmark and trajector are in contact; and (3) what kinds of landmarks and trajectors 'over' encodes. The central sense of 'over' in Dutch is 'extending from a point or a region at one side of $\mathrm{X}$ to a point or region at the other side of $X$, while crossing $X$ ' (p. 52). This last phrase is crucial, as the central sense has a dimension of motion both with and without contact between landmarks and trajectors. Compare, for example, 'De bal rolt over de lijn' [The ball rolls over the line (to the other side of it)] and 'Het vliegtuig vliegt over de stad' [The plane flies over the town (to the next one)]. While 'over' entails contact in the first example, there is no contact entailed in the second one. Geeraerts' analyses are normally very clear, but example 40 from the chapter seems less so. In 'The cloud drifted over the monument,' cloud (the trajector) is said to be a 'surface' although why this is so is not obvious. That said, Geeraerts' findings with respect to 'over' in Dutch show us how rich the semantic structure of prepositions can be. It is perhaps for this reason that cognitive linguists find prepositions fascinating.

5 In chapter 4, 'Salience Phenomena in the Lexicon. A Typology,' Geeraerts suggests that onomasialogy is just as important - and perhaps more so in cognitive linguistics - than is semasiology. If 'salience is the place where structure and use meet' (p. 75), this could be another way of saying that salience is where semantics meets pragmatics. Definition by division is one of Geeraerts' preferred rhetorical techniques, and in this chapter he argues that there are four types of salience phenomena. First, there is perspectival salience involving profiles and bases, or figures and grounds. 'Hand' is normally the 
terminal part of the arm, for example, in relation to the base 'arm.' Likewise, the verb 'sell' profiles the seller while the verb 'buy' profiles the buyer. Examples like these reveal perspectival salience. Second, there is semasiological salience when one word can refer to many concepts. For instance, 'in' prototypically refers to containment rather than inclusion (p.80), so containment is semasiologically salient with the preposition 'in.' Third, there is onomasiological salience when one concept can be represented by many words. Geeraerts' examples here come from his well-known research on clothing terms in Dutch and Flemish. The same item of clothing, for example, is called 'legging' in Dutch yet 'caleçon' in Flemish. Fourth, there is structural salience, which is part of onomasiological salience when it is divided into pragmatic and structural halves. Here Geeraerts discusses data from the domain of Belgian beer. While the referential feature of 'added herbs' is less salient or carries less weight in Belgian beer brands, the referential feature of 'Trappist beer' is apparently more highly valued and thus carries greater weight (p. 89). Geeraerts' study of 469 Belgian beer brands - reprinted in full in chapter 10, 'Beer and Semantics' - reminds us not only that linguistic analysis can be fun but also that our findings might be relevant to those in the private sector.

6 In chapter 5, 'Vagueness's Puzzles, Polysemy's Vagaries,' Geeraerts looks at the question of 'how to identify the polysemous readings of a lexical item' (p. 100). Polysemy was often overlooked by generative linguists, but Geeraerts maintains it was as important for pre-structural linguists as it is today for cognitive linguists. Instead of defining cognitive linguistics as radically different from previous forms of linguistics, Geeraerts reminds us here - and throughout the book - that it more or less continues a tradition that was interrupted briefly by generative linguists. As for the criteria for polysemy, Geeraerts identifies three of them. First, there is Quine's truth-theoretical or logical test for items that are true and false at the same time (i.e. $p$ and not $p$ ). For example, 'Sandeman is a port (wine) but not a port (harbor)' reveals that 'port' may be polysemous. Second, there is the identity or linguistic test. To say, 'At midnight the ship passed the port and so did the bartender' feels odd when both the wine and harbor meanings of 'port' are evoked, even though these meanings suggest that 'port' is vague. Third, there is the definitional test in which the challenge is to define a word such a 'port' in a way to captures all of its meanings (e.g. wine and harbor) accurately. Test three is important for Geeraerts for 'it is the only one that embodies a hypothesis about the principles of categorization' (p.113). After these three tests are introduced, Geeraerts then explains what their limitations are. Consider this example: 'Daddy, is an olive a fruit?' 'Well, it is and it is not' (p. 116). While the logical test may suggest that 'olive' is polysemous (i.e. $p$ and not p), Geeraerts finds that the linguistic test does not reveal the word to be polysemous even though we might expect it to. After all, it is fine to say 'An orange is a fruit and so is an olive.' The problem is one of prototypicality with respect to the FRUIT category. The olive is a more peripheral member of the FRUIT category than is an orange. While one test may suggest the word is polysemous, yet another might suggest it is merely vague. The distinction between polysemy and vagueness is hard to maintain, as Geeraerts' discussion of the Dutch word 'vernederen' (to bring down) also demonstrates. As Geeraerts honestly admits near the end of this chapter:

What we started looking out for was a unique meaning, i.e. the meaning of an utterance, the authentic and original one that the author put in the message (or perhaps: highlighted) and that is objectively there for us to be unpacked (or 
alternatively: observed). But disconcertingly, we have serious difficulties in pinning down the unique meaning of an utterance, not least because the various perspectives that we adopt yield different answers to our semantic question. However, if we abandon the vestiges of objectivism in our methodological selfconception, the presupposition that there is a unique meaning itself can be rejected (p. 139).

7 These are sober words for the linguist on a permanent quest for the Holy Grail of lexical semantics. However, Geeraerts forces us to think about this presupposition because it could very well be the case that the trouble polysemy poses for descriptive linguists is merely 'a side-effect of the interpretative nature of linguistic semantics' (p. 141).

In chapter 6, 'Classical Definability and the Monosemic Bias,' there is a long discussion of methodological problems facing the lexical semanticist. Monosemic bias for Geeraerts refers to the preference in lexical semantics for single meanings rather than many for any given lexical item. Classical definitions can either define 'all and only the members of the category,' or they may 'uniquely define the category' (p. 153). The trouble is that 'not all lexical categories can be classically defined' (p. 167-168), as an analysis of Dutch terms for "legging" and "vest" reveal. Geeraerts' talent for experimental design is obvious here given his use of both onomasiological and semasiological methods. One semasiological question here is what kinds of clothes are called 'vest.' In this case our answers move from world to word. The onomasiological question here is what 'vest' can refer to. In this case our answers move from word to world. As Geeraerts suggests, facing both questions can be fruitful rather than fruitless. After discussing problems with the approaches of Ruhl and Wierzbicka, he notes that the ideal of classical definability conflicts with the monosemic bias (p.172). Lexical semanticists must admit they cannot have it both ways. That is, they cannot maintain a monosemic bias for defining words on the one hand while clinging to the ideal of classical definability on the other. Simply put, lexical semanticists should realize there has to be a better way of doing things if they aim to do semantics properly.

In chapter 7, 'The Semantic Structure of the Indirect Object in Dutch,' Geeraerts looks mainly at ditransitive constructions in order to better define the nature of the Dutch indirect object in such constructions. For example, in 'Hij gaf haar een roos' (He gave her a rose), the direct object of transfer is the rose while the indirect object is the recipient. For Geeraerts, 'If the prototype case of the indirect object construction is defined as "the active recipient (with controlling power) of a benefactive transfer of material entities," various semantic extensions appear to start from each of the aspects of the prototype' (p.191). The first extension is generalization with respect to the beneficiary, who may be the recipient of a material, abstract, or communicative transfer (p.181). The second extension is metaphorization whereby the recipient of a concrete object can be metaphorized as the recipient of an abstract message. The third extension is metonymy, which Geeraerts recognizes is a common kind of extension. For example, in 'Hij schrijft het stadhuis een brief' (He writes the town hall a letter), the recipient is defined by metonymic association with a building or office. The fourth extension is subjectification. For instance, in 'Het is me wat' (That's something to me / as far as I'm concerned), the speaking subject is the indirect object and thus subjectively becomes part of the relationship described. The fifth extension is perspectival switching. For instance, in 'Hij nam haar het speeltje af' (He took the toy from her), there is a negative form of transfer such that it makes more sense to see the recipient as an 'affected entity' rather than see 'her' as a beneficiary since she loses the 
toy instead of getting it. Geeraerts frequently argues in favor of multidimensional analysis, and he makes the same argument here, especially when it helps us overcome limitations, for example, that Goldberg and Rudzka-Ostyn came up against in their analyses of ditransitive constructions.

In chapter 8, 'The Interaction of Metaphor and Metonymy in Composite Expressions,' Geeraerts looks into the prismatic structure of idiomatic expressions. The prismatic structure entails both a paradigmatic dimension (i.e. the original and derived meanings of the idiomatic expression) and a syntagmatic dimension (i.e. how the parts relate to the whole in an interpretation of the idiomatic expression). Geeraerts' concern is with the 'expression as a whole in its derived, idiomatic meaning' (p. 200). Isomorphism exists, for example, when we find correspondences between items in the expressions and elements in the discourse situation. In fact, our minds are on a constant 'search for isomorphism' when faced with idiomatic expressions (p. 209). We may say 'De koe bij de horens vatten' (To take the cow/bull by the horns) in order to mean 'to tackle a problem or difficulty at the central, most dangerous or difficult point' (p. 203). But whereas this idiomatic expression demonstrates isomorphism, our paraphrase of it does not. We can derive the paraphrase from the expression, but it is hard to derive the expression from the paraphrase in bottom-up fashion (p. 203). As for what motivates the creation of idiomatic expressions, Geeraerts notes that etymologists may disagree with each other because reconstructing the historical context that first motivated the expression when it was coined is never an easy affair. And inventing just-so stories to explain the origins of idiomatic expressions will get us nowhere. With respect to the interaction of metaphor and metonymy, Geeraerts looks at the example of 'schapenkop,' which literally means 'sheep's head' but figuratively means 'stupid person' (p. 213). What his prismatic model allows us to do is follow the metaphoric and metonymic steps that take us, for example, from sheep's head to stupid person. Other examples analysed like this include 'in de stront zitten' (to sit in the shit, meaning to have problems), 'droogkloot' (dry testicle, meaning dull man), and 'to catch someone's ear' (to get someone's attention). The true value of Geeraerts' work can be seen here because of his ability to propose solutions to problems found in models proposed by others. Indeed, this may be the reason for being for many of his articles. In chapter 8 , for instance, he ends with a discussion of Goossens' idea of metaphor within metonymy to show how the prismatic model more thoroughly accounts for the data. His desire to find solutions to problems undoubtedly makes Geeraerts' work of great value for the field.

11 In chapter 9, 'Looking Back at Anger: Cultural Traditions and Metaphorical Patterns,' Geeraerts continues to solve problems by pointing out limitations with Kovecses' ahistorical account of expressions of anger. Geeraerts turns to the history of medicine, notably the doctrine of the humors, to contextualize our cultural understanding of emotions. Languages such as English, French, and Dutch still contain 'lexical relics' of Medieval humoral doctrine. These can be seen in phrases such as 'phlegmatic,' 'spleen,' 'bilious,' and 'full-blooded' in English; 'avoir un flegme imperturbable,' 'mélancolie,' 'colère,' and 'avoir du sang dans les veines' in French; and 'valling,' 'zwartgallig,' 'z'n gal spuwen,' and 'warmbloedig' in Dutch. For Geeraerts, remembering this cultural history is vital since, without it, we could hardly understand English terms like 'gall,' 'liverish,' 'choler(ic)' and 'to stir one's bile' (p. 238). The value of the humoral hypothesis for Geeraerts is in the clarity it offers to the analysis of the ANGER IS HEAT conceptual metaphor, which underlies statements such as 'He was filled with anger.' 
Without an understanding of humoral doctrine, it is not clear why we should imagine the body to be a container for the emotions or why emotions should be imagined as fluids in that container. For Geeraerts, 'if the physiological conceptualization of anger (as typically embodied in physiological metaphors) precedes the humoral theory, the only way to establish this is by doing historical research' (p. 247). In other words, there must be more to conceptual metaphor analysis than mere identification of the metaphor. After all, our cultural models have 'a historical dimension' (p. 250). That is why Geeraerts argues that cognitive semantics cannot ignore the history of ideas.

Although the findings from chapter 10 - 'Beer and Semantics' - are summarized in chapter 4 , chapter 10 offers ample support for the opinion that cognitive linguistics should consider itself blessed to count effective rhetoricians among its ranks. As Geeraerts notes, linguistics cannot answer the question of whether or not Belgian beer names reflect the self-conceptions of Belgians (p. 269), especially their 'antiauthoritarian transgressive' side when compared historically to the Dutch. However, it would be a mistake to ignore the social aspects of language. For instance, in chapter 11, 'Cultural Models of Linguistic Standardization,' Geeraerts examines how rationalist and romantic models of language have interacted with nationalist and postmodern models. For the rationalist, standard languages are geographically general whereas dialects are geographically specific. Standard languages are also assumed to be neutral because of their generality, and they are supposed to be the means for participation in democracy and emancipation from ignorance. As Barère stated at the Revolutionary Convention in 1794, 'Citoyens, la langue d'un peuple libre doit être une et la même pour tous' (p. 276). For the romantic, standardized languages oppress rather than liberate. Also, rather than being neutral or geographically general, they are elite and originate in the centers of power.

In contrast to the rationalist, who sees language as a form of communication, the romantic sees language as a form of expressing identity and power. In contrast to the rationalist, who sees in standard language the democratic ideal of participation, the romantic sees standard language as a tool for social exclusion. In contrast to the rationalist, who sees variation as a problem in communication, the romantic sees variation as a vehicle for expressing a unique identity (p. 285). As the example of $19^{\text {th }}$ century French suggests, the rationalist and nationalist models interacted in the standardization of French as it was promoted through educational policy. But the nationalist model was also under romantic influence when believing that a speech community expresses its identity through language. When that community is a nation, then 'the romantic notion of national identity' impacts the nationalist model (p. 291). The paradox of the $19^{\text {th }}$ century involved the tension between social diversity and national homogeneity, but this is why strains of nationalism can be found in both rationalist and romantic models. As for the $20^{\text {th }}$ century, Geeraerts sees the oppositional nature of postmodernism as a form of romanticism that 'revives the claims for diversity' (p. 293). The defense of local languages in the face of global English, for instance, is one place where postmodern and romantic models meet. More interesting, however, is Geeraerts' discussion of how Flemish was standardized on the model of Dutch. The difference today is that colloquial Flemish is more different from standard Flemish than is colloquial Dutch from standard Dutch. As Geeraerts admits, however, it is not possible to predict if colloquial Flemish will become more formal or standard, if formal or standard Flemish will become more colloquial, or if the status 
quo will be maintained. Whatever the result, the models outlined by Geeraerts will no doubt help linguistics better understand future development in Flemish.

Although chapter 12, 'Caught in a Web of Irony: Job and His Embarrassed God,' may be of less interest to linguists (dealing, as it does, with God's speech in the Book of Job), chapter 13 on 'The Lexical Treatment of Prototypical Polysemy' may be of greater interest to linguists. For the lexicographer, two fundamental questions involve what words to include in a dictionary, and what information to include for each of those words. Although Geeraerts agrees with Wierzbicka in theory that 'prototypical concepts are "encyclopedic" entities that should be described in all relevant aspects' (p. 329), in practice lexicography is different - unless, that is, one dreams of creating long dictionaries containing few words. Simply put, 'there is a distinction between theoretical semantics and practical lexicography' (p.330). The lexicographer confronting the issue of polysemy is faced with the linearization question: Is there a way to represent radial categories in a satisfactory manner in the standard print dictionary? One answer may be to use 'hierarchical structures in a non-taxonomical way' (p. 343) to respect phenomena such as indeterminacy and overlapping meanings. Geeraerts' example of how this could work comes from the Dutch word 'vers' (fresh) in the Woordenboek der Nederlandsche Taal - the Dutch OED. As he shows, there are seven main groups gathering together twenty-one separate meanings of 'vers' in the Dutch dictionary. Some meanings (e.g. 'in an optimal condition' and 'recent, new') are more prototypical than others (e.g. food not have been treated in any way). Geeraerts argues persuasively that astute lexicographers who grasp the nature of semantic prototypes can not only begin to address the linearization question, they can also become more committed to their data and less committed to their theories when their data undermine those very theories. As he states later in the book, if 'any traditional form of linear ordering cannot do full justice to the multidimensional nature of semantic structures' (p. 361), lexicographers would be wise to openly admit this fact.

In chapter 14, 'The Definitional Practice of Dictionaries and The Cognitive Semantic Conception of Polysemy,' Geeraerts notes that cognitive semantics has influenced lexicology in three ways (p. 346). First, the value of prototypicality effects for lexical structure has been recognized. Second, given that polysemy may be the rule rather than the exception in language, word meaning has been recognized as flexible. Third, polysemy maintains a radial set structure. Using 'fruit' as an example, Geeraerts explains that at the semantic level it refers primarily to the 'edible part of the plant'. At the referential level this meaning can be represented by items such as apple, orange, pear, banana, or avocado (p.353). At the semantic level, the meaning can also be extended metaphorically to include 'result of an action,' as in 'the fruit of labor', or it can be extended generally to include the 'seed-bearing part of a plant.' In turn, those two extended meanings at the semantic level can themselves be embodied by new examples at the referential level. These levels, of course, are not rigid; rather, the division merely allows us to see how word meaning may vary between generic and specific poles. A dozen other examples explored by Geeraerts are from the New Shorter OED of 1997, and they range from 'abiogenesis' to 'thimblerig'. In a brilliant passage, Geeraerts writes: 'In each of these definitions, words such as especially, e.g. typically, usually, and often introduce descriptive features that are not general but that rather identify typical (prototypical, if one likes) characteristics or instances of the category. Within a structuralist conception of semantics, this would be inadmissible, because these elements belong to the 'encyclopedic' level rather than the semantic level. In 
actual practice, however, this prototype-oriented definitional technique can hardly be called exceptional in the context of the dictionary as a whole. The expression esp. [especially], for instance, is used no less than 28,335 times in 18,274 entries in the dictionary as a whole' (p. 356). This brings us back to a point raised in the book's first chapter: since prototype theory helps us re-define linguistics as a cognitive science, it is not clear why generativists (who, after all, first proposed this re-definition) overlooked the relevance to linguistics of prototype research in psychology for so long. As Geeraerts makes clear throughout this book, cognitive linguistics has helped linguistics reconcile itself with its pre-structural tradition. But as he suggests at the end of this chapter, we still have work to do, including the incorporation of current corpus linguistic methodology into cognitive linguistics. Simply put, usage-based theories of language ought to take the findings of corpus linguists into account. If they do not, then they might have to abandon their status as usage-based theories.

In chapter 15, 'Cognitive Grammar and the History of Lexical Semantics,' Geeraerts reminds us that cognitive linguistics has some roots in the historical-philological linguistics of the late $19^{\text {th }}$ and early $20^{\text {th }}$ centuries. The three major aspects of historical-philological linguistics were: (1) its historical orientation, which was adopted for the purpose of studying semantic change; (2) its psychological orientation, which located language within general cognitive capabilities; and (3) its hermeneutical orientation, which firmly situated the new discipline of linguistics within the interpretative (or human) sciences. To compare historical-philological linguistics with cognitive semantics, Geeraerts identifies nine hypotheses of cognitive semantics: (1) lexical concepts have fuzzy rather than rigid boundaries; (2) polysemous meanings may overlap rather than be neatly separated; (3) categories cannot be defined in terms of the inherent attributes of all the category's members; (4) lexical concepts can be defined disjunctively rather than conjunctively since - and this is hypothesis (5) - the attributes of prototypes are less common for peripheral members of the same category; (6) lexical concepts are flexible rather than rigid and analogical rather than algorithmical; (7) language is part of human cognition rather than independent of it; (8) semantic definitions of lexical concepts and encyclopedic definitions of the same cannot in principle be separated; and (9) cultural contexts and other relevant data should not be ignored in the study of semantics.

Historical-philological linguistics and cognitive linguistics share a psychological orientation and a rejection of the belief that language is an autonomous faculty. Both schools of thought also have similar views about 'the nature of semantic categories' (p. 380) even though this similarity is not very well known. But whereas the synchronic focus of the structural approach imagined language to be static, diachronic and synchronic concerns combine in the cognitive approach because of the belief that language is dynamic. After all, 'a steady state can hardly be found in linguistic reality' (p. 382). In what is perhaps the most impressive section of the chapter, on the history of lexical semantics, Geeraerts shows how lexical semantics has oscillated 'between an autonomous and an experiential, psychological approach' (p. 393). As Geeraerts warns us at the end of the chapter, although structural and transformational semantics have run out of steam, it is misguided to think of cognitive semantics as 'a mere return to pre-structuralist semantics' (p. 395). It would be equally misguided to think of cognitive semantics as an entirely novel approach since an awareness of the history of linguistics would enable us to see that this is not altogether true. In short, reconsidering previous schools of thought in linguistics permits us to see what makes cognitive linguistics both 
similar and different from earlier traditions. Without an awareness of that intellectual history, however, we run the risk of misunderstanding cognitive linguistics.

In chapter 16, 'The Theoretical and Descriptive Development of Lexical Semantics,' Geeraerts breaks the history of lexical semantics into four parts (p. 399). First, the period between 1870 and 1930 or so saw the rise of pre-structuralist semantics. Second, the period between the 1930s and the 1960s saw the rise of structuralist semantics. Third, the period between the 1960s and the 1980s saw the rise of generativist semantics. Fourth, the 1980s and 1990s witnessed the initial stages of formation of cognitive semantics. This is not to say that cognitive semantics is the only kind semantics around today; indeed, new versions of structural or generative semantics can now be found in what Geeraerts calls neo-structuralist and neo-generative semantics. But as he correctly indicates, cognitive semantics has brought to lexicology an awareness of metaphor, scenes and frames, prototype theory, and the naming preferences found at the basic levels of categories. Within lexical semantics there has always been a tension between restrictive approaches on the one hand and encyclopedic approaches on the other. As Geeraerts argues, the 'core area of lexical semantics [is] the synchronic (rather than diachronic) structure of referential (rather than non-referential) meanings' (p. 409). Lexical semantics as a field can be mapped in terms of the qualitative and quantitative dimensions of semasiology and onomasiology. Whereas cognitive semantics typically focuses on the quantitative dimension of both semasiology (e.g. prototype theory) and onomasiology (e.g. basic levels and entrenchment), pre-structuralist semantics often focused on the qualitative dimension of semasiology while structuralist semantics usually focused on the qualitative dimension of onomasiology. To his credit, Geeraerts realizes there is a risk in oversimplifying different approaches to lexical semantics (p. 412). He also gives praise where it is due by welcoming, for example, the rise of collocation analysis in corpus linguistics because it gives neo-structuralist semantics a usage-based perspective (p. 415). In sum, Geeraerts tells an interesting story here about the development of lexical semantics.

The final chapter, 'Idealist and Empiricist Tendencies in Cognitive Semantics,' takes the form of a dialogue between three characters. Geeraerts clearly has a sense of humor, which is a virtue in linguistics. As he argues, cognitive linguistics wavers between two methodological extremes. On the one hand, there is an empirical or objective and datadriven approach often taken by those like Geeraerts. On the other hand, there is an idealistic or subjective and introspective approach often taken by those like Wierzbicka. While the Duodecimus Empiricus character is apparently modeled on Geeraerts, the Antipoda Proliphica character is apparently modeled on Wierzbicka. The third character is Histrio Polymorphus, an old professor and mentor to the first two characters. To summarize this long dialogue would not do it justice, but it covers a range of interesting topics, including Kuhnian paradigms, falsifiable hypotheses, and Dilthey's fear of 'romantic arbitrariness' in the human sciences. Linguistics is an interpretative discipline, but that should not compel it to be an entirely subjective one. In this dialogue, Geeraerts makes the case for his preference for the empirical approach although he admits, in all fairness, that much cognitive linguistic research contains aspects of both approaches. As he warns us at the very end of the book, we should remember Dilthey's concerns since 'what constitutes a legitimate interpretation of natural language expressions' (p. 443) isn't an easy question to answer. By facing it, 
however, we can begin to regard our own research with a critical eye in order to see if we are doing accurate and honest work.

In conclusion, linguists have a lot to gain and little to lose by reading this book, especially if they never read these articles by Geeraerts when they were first published. As Geeraerts reminds us again and again, multidimensional semantic analysis has its rewards although we must always remain on guard against methodological hubris. As for the book's faults, there is the occasional typographical error, the inclusion of chapter 12 is debatable, and some of the data are discussed more than once. But to be fair, those drawbacks are not uncommon in books that gather together individual articles that were previously published in separate fashion over fifteen years. Finally, allow me to add that whenever Geeraerts is critical, his critiques are never gratuitous. On the contrary, they reveal how we can pick up where others have left off by proposing solutions to problems or answers to questions that may have frustrated our predecessors. That is why even those who disagree with Geeraerts may find this book to be useful.

\section{AUTHORS}

\section{CRAIG HAMILTON}

Craig Hamilton, Université de Haute Alsace, France.

Craig Hamilton is MCF in English Cognitive Linguistics at the Université de Haute Alsace. His research re-defines rhetoric and poetics within the framework of cognitive linguistics. He did his $\mathrm{PhD}$ at the University of Maryland, where he studied with Mark Turner. In 1999-2000, he held a Chateaubriand Fellowship at CREA (Ecole Polytechnique, CNRS UMR 7656). Before moving to Alsace, Craig taught at the University of California in Irvine, the University of Nottingham in England, and the Université de Paris 8. 